\title{
Respiratory Frequency According to Sleep States and Age in Normal Premature Infants: a Comparison with Full Term Infants
}

\author{
L. CURZI-DASCALOVA ${ }^{(24)}$ F. LEBRUN, AND G. KORN \\ INSERM-U2G Centre de Recherche de Biologie Foetale et Néonatale, Hôpital Port-Royal, Paris, France \\ [L. C.-D., G. K.] and Clinique Universitaire Baudelocque, Université René Descartes, Paris, France [F. L.]
}

\begin{abstract}
Summary
To assess the influence of sleep states, gestational age, and postnatal age on respiratory frequencies, we made polygraphic recordings on forty-eight 31-41 wk gestational age newborns $(\leqslant$ 10 days of legal age) and on 16 prematurely born $(\leqslant 36$ wk of gestation) infants, after they reached the term of 37-40 wk conceptional age. Periods with and without $\geqslant 3$-sec respiratory pauses were independently analyzed by 20 -sec periods. States of sleep were defined according to REMs and EEG criteria.

At all ages and in all sleep states, respiratory frequencies were slightly, but not significantly, lower in total tracing compared to no-pause tracing. Results of statistical comparison were identical when they were performed on both total and no-pause tracings.

From 35 wk gestational age onward, respiratory frequency was higher in active (AS) REM sleep, compared to quiet (QS) NREM sleep $(P<0.01)$. In undefined sleep (IS), respiratory frequency was at an intermediate level (AS > IS > QS), significantly different from that of $A S$ and QS.

Respiratory frequency was similar in all 31-38 wk gestational age newborns. It became significantly higher in 39-41 wk gestational age newborns $(P<0.01)$.

The frequency of the respiration was higher in prematurely born infants reaching 37-48 or 39-40 wk conceptional age, compared to that of newborns of the same gestational age.

We did not find significant differences between genders in any age group studied.

At all ages there was a high correlation among respiratory frequencies found in $\mathrm{AS}, \mathrm{QS}$, and IS and also among those frequencies found in successive sleep cycles for given individuals: some normal infants breathed more rapidly and the others more slowly in all states studied. It appears that respiratory frequency is an individual characteristic, modulated by the sleep state, gestational age and postnatal age factors.
\end{abstract}

The review of the literature suggests, that divergences among authors can be due to some methodological differences and particularly to differences in scoring of sleep states.

Abbreviations

AS, active sleep

$\mathrm{CA}$, conceptional age

GA, gestational age

IS, undefined sleep

QS, quiet sleep

RF, respiratory frequency

Respiratory rate is one of the characteristics of sleep states in normal full-term newborns and in infants during the first months of life: at this age, respiratory rate is irregular and faster in active sleep (AS), more regular and slower in quiet (QS) sleep $(15,18$, other references in 5).
Respiration of premature infants has been described as irregular in AS and more or less regular in QS $(8,17)$. Respiratory frequency (RF) of prematures has been studied more recently. The age groups, the criteria of a normality and the method of sleep state definition differs from one author to another. The results obtained were variable (see review Table 1).

The complexity of the factors, that can influence RF in premature infants encouraged us to undertake this investigation. Our aim was to test the effect of sleep states, gestational age (GA) and postnatal age on RF. The importance of sleep state defininition in very young infants will be especially discussed.

\section{MATERIALS AND METHODS}

This study was carried out on 48 normal, 31-4l wk CA (Conceptional age is gestational age at birth plus postnatal age) infants, recorded during the neonatal period (up to 10 days of legal age) and in 16 prematurely born infants recorded when they reached the term of $37-40$ wk conceptional age.

Normal premature infants were selected between 1976 and 1979 from the population of the Port-Royal Hospital and the Baudelocque Clinic (Paris) departments for normal premature infants.

Age and normality of the infants were determined according to the following criteria: first day of the last menstrual period; clinical and neurologic examination (21); physical measurement of weight, body length, and cephalic perimeter (12) and the EEG pattern (references in 9). The Apgar score at $5 \mathrm{~min}$ of life is $\geqslant 7$ for premature, $\geqslant 9$ for full-term infants. The infants did not have any respiratory pathology. Recordings were performed in the hospital EEG laboratory, during the morning, between two meals. All 3741 wk term infants were normally dressed, lying in their own cots, at a room temperature of $25-26^{\circ} \mathrm{C}$. Premature infants were in incubators at $30-36^{\circ} \mathrm{C}$. Incubator temperature was at the level necessary to maintain normal body temperature. All infants were in the supine position. Polygraphic tracings included EEG, ECG, eye movements (recorded with piezoelectrical quartz accelerometer), thoracic, and abdominal respiratory movements and air flow recordings. The method of recording has been previously described (3).

Infant behaviour was monitored throughout the recording by two independent observers.

The sleep states were defined according to two criteria: (1) $E E G$ patterns, characteristic for AS and QS for the given conceptional age (references and details in 9) and (2) rapid eye movements (REMs), which were present in AS but absent in QS. The beginning of one AS or QS state was defined by the simultaneous presence of the EEG and REMs criteria for at least 1 min (14). All periods with a discrepancy between these two criteria were classified as undefined sleep (IS).

All infants had at least one sleep cycle, including a complete ( $\geqslant 5$ min duration) AS and QS state. Thirty-eight of them had two 
Table 1. Respiratory frequency studies of premature infants according to the literature ${ }^{1}$

\begin{tabular}{|c|c|c|c|c|c|c|c|c|c|c|}
\hline \multirow[b]{2}{*}{ Authors } & \multirow[b]{2}{*}{$N$} & \multicolumn{3}{|c|}{ Age } & \multirow[b]{2}{*}{$\begin{array}{l}\text { Criteria of } \\
\text { normality }\end{array}$} & \multirow[b]{2}{*}{$\begin{array}{c}\text { Sleep state } \\
\text { criteria }\end{array}$} & \multirow[b]{2}{*}{$\begin{array}{l}\text { Duration of } \\
\text { studied pe- } \\
\text { riods }\end{array}$} & \multicolumn{3}{|c|}{ Respiratory frequencies/min } \\
\hline & & $\begin{array}{l}\text { Gesta- } \\
\text { tional } \\
\text { (wk) }\end{array}$ & $\begin{array}{r}\text { Legal } \\
\text { (days) }\end{array}$ & $\begin{array}{l}\text { Concep- } \\
\text { tional } \\
\text { (wk) }\end{array}$ & & & & in $\mathrm{QS}^{2}$ & in $\mathrm{AS}^{2}$ & $P<$ \\
\hline $\begin{array}{l}\text { Iwase and } \\
\text { Watanabe } \\
(1971)\end{array}$ & 7 & & & $32-40$ & $\begin{array}{l}\text { Uncompli- } \\
\text { cated deliv- } \\
\text { ery and } \\
\text { normal } \\
\text { growth }\end{array}$ & $\begin{array}{c}\text { REM versus } \\
\text { "trace al- } \\
\text { ternant" }\end{array}$ & & 50 & 50 & \\
\hline \multirow[t]{2}{*}{$\begin{array}{l}\text { Davi et al. } \\
\text { (1979) }\end{array}$} & 10 & $28-35$ & $8-59$ & $32-38$ & "healthy" & $\begin{array}{l}\text { Rechtschaffen } \\
\text { and Kales } \\
\text { (1968) cri- } \\
\text { teria, REM } \\
\text { (oculo- } \\
\text { gram) mon- } \\
\text { itoring, } \\
\text { EEG }\end{array}$ & & $49 \pm 5$ & $55 \pm 6$ & $\mathrm{NS}^{2}$ \\
\hline & 10 & $38-42$ & $1-7$ & $38-42$ & "healthy" & idem & & $43 \pm 3$ & $52 \pm 4$ & 0.05 \\
\hline \multirow[t]{3}{*}{$\begin{array}{l}\text { Siassi et al. } \\
\text { (1979) }\end{array}$} & 9 & $27-33$ & $2-6$ & & $\begin{array}{c}\text { free from car- } \\
\text { diopulmon- } \\
\text { ary disease }\end{array}$ & $\begin{array}{l}\text { REM + body } \\
\text { motility } \\
\text { (visual ob- } \\
\text { servation) }\end{array}$ & $\begin{array}{l}\text { total duration } \\
\text { of tracings? }\end{array}$ & $44 \pm 12.0$ & $45 \pm 10.2$ & NS \\
\hline & 14 & $34-36$ & $1-6$ & & idem & idem & idem & $39 \pm 12.3$ & $41 \pm 12.3$ & NS \\
\hline & 9 & $37-40$ & $2-6$ & & idem & idem & idem & $36 \pm 13.0$ & $35 \pm 14.7$ & NS \\
\hline $\begin{array}{l}\text { Rigatto et al. } \\
\quad(1980)\end{array}$ & 5 & $32 \pm 1$ & $30 \pm 5$ & & $\begin{array}{l}\text { preterm in- } \\
\text { fants }\end{array}$ & $\begin{array}{l}\text { see Davi et al. } \\
(1979) \text { cri- } \\
\text { teria }\end{array}$ & & $\begin{array}{l}29 \pm 5 \text { in pe- } \\
\text { riodic } \\
\text { breathing } \\
42 \pm 6 \text { in regu- } \\
\text { lar breathing }\end{array}$ & $\begin{array}{l}39 \pm 1 \text { in pe- } \\
\text { riodic } \\
\text { breathing } \\
54 \pm 3 \text { in regu- } \\
\text { lar breathing }\end{array}$ & \\
\hline $\begin{array}{l}\text { Messer et al. } \\
\text { (1981) }\end{array}$ & 12 & $31-37$ & $1-5$ & $36-38$ & $\begin{array}{l}\text { Healthy; } 4 / 12 \\
\text { small for } \\
\text { date; Apgar } \\
\geq 7 \text { at } 1 \\
\text { min, Apgar } \\
=10 \text { at } 5 \\
\text { min }\end{array}$ & $\begin{array}{l}\text { EEG, REM } \\
\text { (oculo- } \\
\text { gram), chin } \\
\text { EMG mon- } \\
\text { itoring }\end{array}$ & $\begin{array}{l}15 \mathrm{~min} \text { of } \mathrm{AS} \\
\text { and } 15 \mathrm{~min} \\
\text { of } \mathrm{QS}\end{array}$ & $44.2 \pm 13.3$ & $45.5 \pm 13.7$ & NS \\
\hline \multirow[t]{6}{*}{$\begin{array}{l}\text { Curzi-Dasca- } \\
\text { lova et } \\
\text { al.(present } \\
\text { study) }\end{array}$} & 6 & $30-34$ & $2-9$ & $31-34$ & $\begin{array}{l}\text { Neurologic, } \\
\text { cardio re- } \\
\text { spiratory, } \\
\text { physical, } \\
\text { EEG; Ap- } \\
\text { gar } \geq 7 \text { at } 5 \\
\text { min }\end{array}$ & $\begin{array}{l}\text { EEG + } \\
\text { REMs (ac- } \\
\text { celerome- } \\
\text { ter) moni- } \\
\text { toring }\end{array}$ & $\begin{array}{l}\text { total duration } \\
\text { of tracings, } \\
\text { at least } 1 \\
\text { complete } \\
\text { cycle (AS } \\
+ \text { QS) }\end{array}$ & $32.7 \pm 15.11$ & $36.7 \pm 11.1$ & NS \\
\hline & 10 & $34-36$ & $2-10$ & $35-36$ & idem & idem & idem & $26.5 \pm 6.4$ & $31.6 \pm 8.4$ & 0.001 \\
\hline & 10 & $37-38$ & $2-6$ & $37-38$ & $\begin{array}{l}\text { idem } \\
\text { Apgar }=10 \text { at } \\
\quad 3 \mathrm{~min}\end{array}$ & idem & idem & $29.7 \pm 6.2$ & $34.2 \pm 9.1$ & 0.01 \\
\hline & 22 & $39-41$ & $2-9$ & $39-41$ & idem & idem & idem & $35.6 \pm 7.6$ & $47.1 \pm 8.9$ & 0.001 \\
\hline & 8 & $30-36$ & $13-57$ & $37-38$ & idem & idem & idem & $37.6 \pm 10.7$ & $45.7 \pm 15$ & 0.01 \\
\hline & 8 & $30-35$ & $31-41$ & $39-40$ & idem & idem & idem & $46.6 \pm 5.8$ & $55.3 \pm 6.9$ & 0.02 \\
\hline
\end{tabular}

\footnotetext{
'Legends as in Table 2.

${ }^{2} \mathrm{QS}$, quiet sleep; AS, active sleep; and NS, not significant.
}

or more complete sleep cycles. The tracings lasted from 65-160 min. Total tracing duration was analysed.

RF were counted by 20 -sec periods free of artefacts i.e., without any distortion of the respiratory tracing caused by body movements.

All respiratory pauses of $\geqslant 3 \mathrm{sec}$ duration were noted. The RF was counted both for the whole tracing and when 20 -sec periods containing pauses had been eliminated.
Results were statistically tested by analysis of variance, $t$ tests, and by computing the correlation coefficients.

\section{RESULTS}

$R F$ as a function of sleep states. Table 2 shows mean RF during the first AS and QS at different ages. There were minimal differences between RF in total and in no-pauses tracings. These 
Table 2. Mean respiratory frequencies (RF) per min and standard error of the means during active and quiet sleep according to conceptual age 1

(A) Newborns recorded at $\leq 10$ days of legal age

\begin{tabular}{|c|c|c|c|c|c|c|c|}
\hline \multirow[b]{2}{*}{$\begin{array}{c}\text { Conceptional } \\
\text { age }\end{array}$} & \multirow[b]{2}{*}{$N^{2}$} & \multicolumn{2}{|c|}{$\begin{array}{l}\text { (A) Newborns re } \\
\text { Active sleep (AS) }\end{array}$} & \multicolumn{2}{|c|}{$\begin{array}{l}\leq 10 \text { days of legal age } \\
\text { Quiet sleep (QS) }\end{array}$} & \multicolumn{2}{|c|}{ (As/QS) level of significance } \\
\hline & & Total tracing ${ }^{3}$ & No-pause tracing ${ }^{4}$ & Total tracing & No-pause tracing & Total tracing & $\begin{array}{c}\text { No-pause } \\
\text { tracing }\end{array}$ \\
\hline $31-34$ wk & 6 & $36.7 \pm 11.1$ & $39.8 \pm 12.1$ & $32.7 \pm 15.1$ & $33.5 \pm 15.1$ & NS & NS \\
\hline $35-36 \mathrm{wk}$ & 10 & $31.6 \pm 8.43$ & $34.3 \pm 8.9$ & $26.5 \pm 6.4$ & $26.8 \pm 6.4$ & 0.001 & 0.01 \\
\hline $37-38 \mathrm{wk}$ & 10 & $34.2 \pm 9.1$ & $36.5 \pm 9.3$ & $29.7 \pm 6.2$ & $30 \pm 6.19$ & 0.01 & $0.00 \mathrm{I}$ \\
\hline $39-41 \mathrm{wk}$ & 22 & $47.1 \pm 8.9$ & $47.8 \pm 8.7$ & $35.6 \pm 7.6$ & $36 \pm 7.2$ & 0.001 & 0.001 \\
\hline \multicolumn{8}{|c|}{ (B) Prematurely borns recorded at full-term conceptual age } \\
\hline $37-38 w k$ & 8 & $45.7 \pm 15$ & $47.4 \pm 13.9$ & $37.6 \pm 10.7$ & $38.4 \pm 10.2$ & 0.01 & 0.01 \\
\hline $39-40$ wk & 8 & $55.3 \pm 6.9$ & $58.8 \pm 7.7$ & $46.6 \pm 5.8$ & $48.9 \pm 7.2$ & 0.02 & 0.01 \\
\hline
\end{tabular}

' In all groups and states, there were no significant differences between RF in total and no-pause tracings. For the degree of significance of betweenage differences of RF, see text.

${ }^{2} \mathrm{~N}$, number of infants.

${ }^{3}$ Total tracing and RF counting are carried out before the removal of periods including respiratory pauses.

${ }^{4}$ No-pause tracing, RF during periods without $\geq 3 \mathrm{sec}$ respiratory pauses.

differences were not significant in any age group or state. All further statistical comparisons were identical when calculated using total or no-pause tracings. In all sleep states, there was a correlation between RF found during total tracing and that found during no-pause tracing $(P<0.02$ at $31-34$ wk GA, $P<0.01$ for the other age groups).

The analysis of variance showed that from 35-36 wk CA, the RF was significantly higher in AS, compared to that of QS (Table 2). During IS, RF usually showed intermediate levels (AS $>$ IS $>$ QS) significantly different from RF in AS and in QS $(P<0.05)$.

In 31-34 wk CA prematures, differences of RF between sleep states were not significant.

At all ages, the analysis of variance showed a wide range of variability between RF of individuals; however, RF found in different sleep states were highly correlated $(P<0.01)$ : some infants breathed more rapidly and others more slowly in all sleep states (Fig. 1).

\section{RF DURING THE COURSE OF SLEEP}

$R F$ in successive sleep cycles. In premature, 31-36 wk GA newborns, we observed an acceleration ( $5-6$ breaths/min) of RF during the second AS and QS compared to AS and QS of the first sleep cycle $(P<0.001)$. In $37-38$ wk GA newborns an acceleration (of about 2 breaths/min) was observed only during the second QS, compared to the first one $(P<0.05)$. We did not find significant differences between RF of successive sleep cycles in 39-41 wk GA newborns nor in prematurely borns reaching 37-40 wk CA term.

The values of RF found in the first and in the second sleep cycle showed a highly significant position correlation (for both sleep states: $P<0.05$ at $37-38$ wk GA, $P<0.01$ at the other ages). The infants who breathed more rapidly during the first sleep cycle breathed more rapidly during the second sleep cycle and vice versa.

$R F$ during the course of a given $A S$ and $Q S$ state. We did not find significant differences between the first, the middle and the last min of different sleep states, except for the previously described (5) slowing of RF during the course of QS in 39-4lwk CA newborns $(P<0.001)$.

\section{RF AS A FUNCTION OF AGE}

Three-way analysis of variance showed that in addition to the sleep state differences there were some age-related RF differences. (1) $R F$ in newborns, $\leqslant 10$ days of legal age, Table $2(A)$. There were no significant differences between RF of 31-38 wk GA groups.
RF became significantly faster in 39-41wk GA ful-term newborns, compared to all 31-38 wk GA newborn groups $(P<0.001$ for all sleep state comparisons). (2) RF of prematurely born infants, reaching 37-40wk $C A$, Table $2(B)$. RF of the prematurely born infants reaching 37-38 wk CA was significantly faster compared to that of newborns of the same GA $(P<0.001$ for AS, $P<0.01$ for QS $)$. It was similar to RF of 39-41wk GA newborns. During quiet sleep, RF of prematurely born infants reaching 39-41 wk CA was faster compared to that of 39-41 wk GA newborns. The difference was not significant for AS. Differences between RF of prematurely born infants reaching 37-38 wk CA and those reaching 39-4l wk CA were not significant.

\section{RF AND GENDER}

We did not find any significant differences between RF in male and female infants.

\section{DISCUSSION}

The present study shows that RF is one of the criteria of differentiation between AS and QS in very young infants. From 35 wk CA onward, as for older infants (ref. in 5), RF is significantly higher in AS as compared to QS. In IS, RF is at an intermediate level, significantly different from that of AS and of QS. Our results are not in accordance with those of some other authors $(7,11,13$, 23). We assume that this disagreement may be due to some differences in the choice of the periods studied, the methods of sleep state scoring, and the selection of subjects (Table 1).

\section{CHOICE OF PERIODS}

Brief respiratory pauses and periodic breathing are normal phenomena in premature infants $(8,17$, other references in 22). Rigatto et al. (20) noted that RF is slower in periods that include respiratory pauses; however, our study showed that differences between RF in total-duration tracings and in no-pause tracings were minimal in normal infants. Differences between states and between ages were statistically identical when the comparisons were performed using total and no-pause tracings; therefore, for normal infants, rejecting or including respiratory pauses is probably not the cause of the differences between various RF studies.

$R F$ varies during the course of sleep. This study showed that in prematures RF was faster during the second sleep cycle than the first one. This acceleration may modify results if short periods are used for RF studies. In spite of this acceleration, the difference between states of successive sleep cycles persists. 

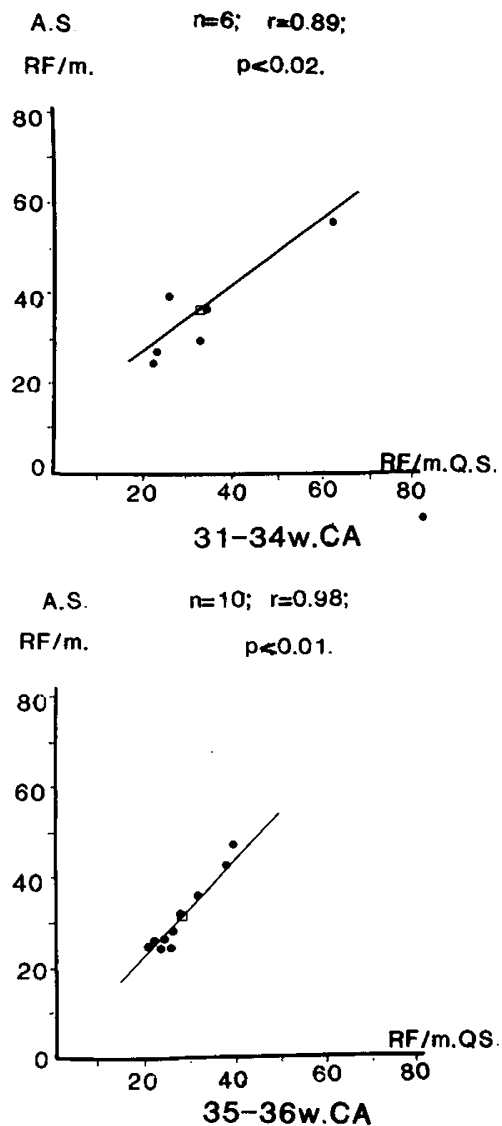
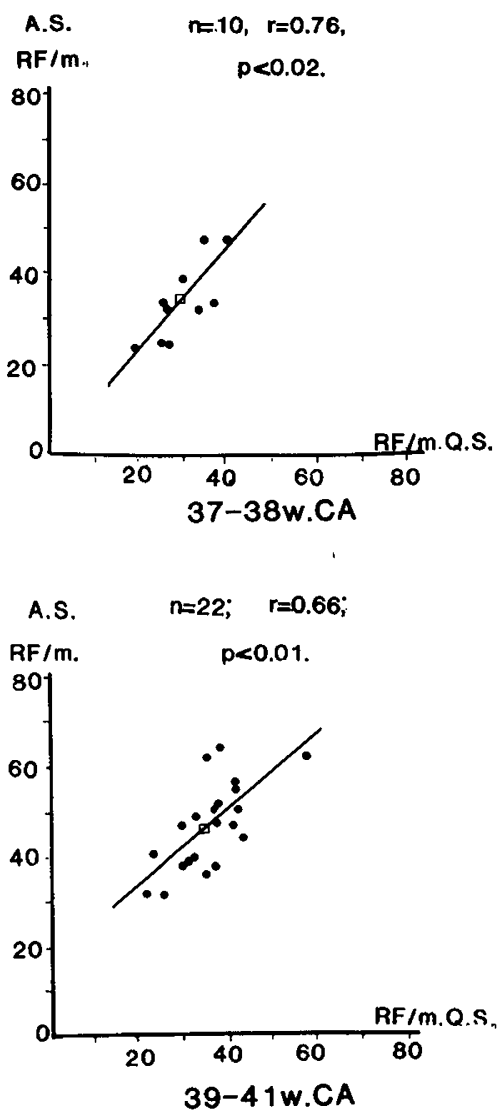

A.S. $n=8 ; r=0.83$;

$\mathrm{RF} / \mathrm{m}$. $\quad p<0.01$.
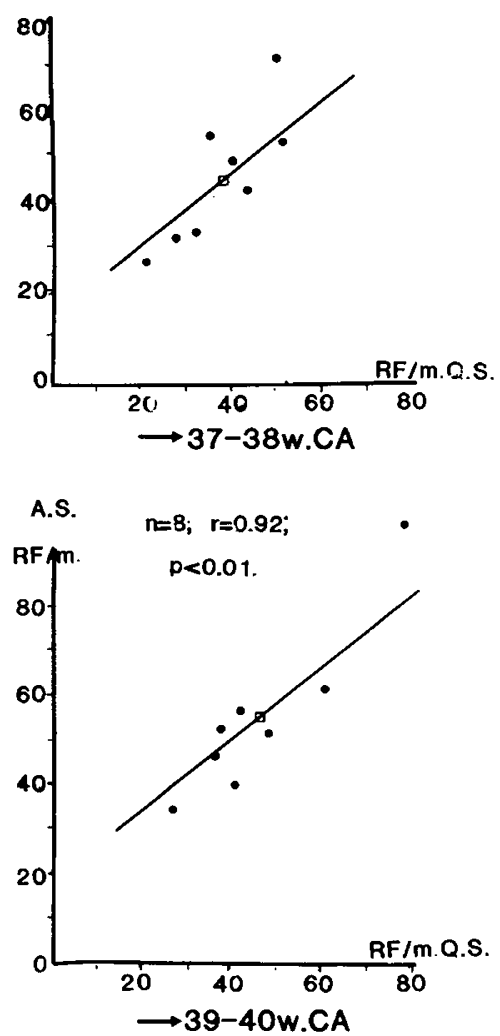

Fig. 1. Correlations between individual respiratory frequencies/min (RF) in total tracing of active (AS) and quiet (QS) sleep at different ages. On the right of the figure, individual RF in 16 prematurely born infants are given when they reached the normal term of $37-38$ and $39-40$ wk conceptional age (CA).

\section{SLEEP STATES CODING}

Sleep states coding in premature infants has not yet been resolved. The works of Dreyfus-Brisac (9) and Dreyfus-Brisac and Monod (10) point out the differences among sleep states characteristics in adults, described by Rechtschaffen and Kales (19) and among those of young infants. Criteria of sleep states described in the Anders et al. manual (1) and especially the "trace alternant," concern only normal full-term newborns.

Dreyfus-Brisac $(8,9)$ showed that at 31-32 wk CA, AS periods with continuous (delta or delta plus theta) EEG and the presence of rapid eye movements can be distinguished from the periods with discontinuous EEG and rare or absent eye movements. Discontinuous EEG and absence of REM characterize QS from about 35 wk CA. Body motility is not completely inhibited and tonic EMG is not constant in QS of premature infants.

The comparative study of Pajot et al. (16) showed that in very young infants, rapid eye movements are not always detected by visual observation or by electrooculographic recording. These authors have found that recording with piezoelectrical quartz accelerometer is a more trustworthy method for detection of rapid eye movement in premature infants. Experience in our laboratory confirms that if the eye movements are not recorded by an accelerometer, some REMs and consequently some periods of AS can be omitted and classified as nonREM QS periods. The transitional or undefined sleep state cannot be distinguished by visual observation of the infants' behaviour (6) and therefore will be scored with one of the well defined AS or QS states.

Using EEG and REMs criteria for sleep state scoring, we found significant between-state differences of RF (AS > IS > QS) from
35 wk CA i.e., at the age when QS becomes well defined as shown by Dreyfus-Brisac $(8,9)$.

Because methods of sleep state scoring and of polygraphic recording are different, it is possible that the results presented by various authors (Table 1) do not relate to identical sleep state periods.

\section{RF AND AGE}

Conceptional age and $R F$. Our study showed that in both sleep states, RF was similar in all groups of newborns from 31-38 wk CA. RF only became significantly higher 39-4lwk CA.

According to international conventions, $37-38$ wk CA infants are classified as full-term newborns; however, according to RF criteria, 37-38 CA newborns are similar to premature newborns, and not to 39-4l wk CA full-term newborns. Differences in the age groupings used by various authors (Table 1) may perhaps modify or reduce the between-state differences.

Postnatal age and $R F$. In prematurely born infants reaching 3738 or 39-40 wk CA, RF was higher compared to RF of newborns of the same term. RF of prematurely born infants reaching 37-38 wk CA was similar to RF of 39-41 wk CA newborns. RF of prematurely born infants reaching 39-41 wk CA was similar to RF of 2-5 wk full-term born infants (5).

Can we assume that prematurely born infants reaching the normal term are more "mature" than the newborns of the same CA? This conclusion is questionable. It has not been confirmed by studies of other respiratory parameters. Contrary to RF findings, respiratory pause frequency in prematurely born infants reaching normal term is similar to that of prematures and higher 
of that of respiratory pauses in 39-41 wk CA newborns (4). On the other hand, our study on the \% of time with out of phase thoracic and abdominal respiratory movements demonstrated identical results in all age groups from $31-41$ wk CA (3).

Differences between degree of maturation of different sleep criteria according to postnatal age were previously reported. Dreyfus-Brisac observed that "the respiratory rate during regular respiration becomes more rapid when the premature attained a conceptional age of $38-41 \mathrm{wk}$, whereas the premature at $40 \mathrm{wk}$ of CA had not attained a level of organization (of sleep states) as high as that of the full-term newborns." Recently, Booth et al. (2) observed that at $41 \mathrm{wk} \mathrm{CA}$, the preterm infant seems more mature than the full-term infant in some of its QS characteristics and appears more immature with respect to some of its AS characteristics.

\section{RF AS AN INDIVIDUAL CHARACTERISTIC}

RF, modulated by sleep state and age factors as discussed above, seems to be an indjvidual characteristic with high significant correlations between the values found in different situations for given individuals. Normal premature infants who breathe more rapidly (or slowly) in one sleep state breathe more rapidly (or slowly) in all the other sleep states. This particularity of RF has been described previously in normal full-term newborns and in babies during the first months of life (5).

In conclusion, it appears that RF during sleep in premature infants is an individual characteristic modulated by sleep state, gestational, and postnatal age factors.

\section{REFERENCES AND NOTES}

1. Anders, T., Emde, R., and Parmelee, A.: A manual of standardized terminology, techniques and criteria for scoring of states of sleep and wakefulness in newborn infants. (UCLA Brain Information Service, BRI Publications Office NINDS Neurological Information Network, 1971)

2. Booth, C. L., Leonard, H. L., and Thoman, E. B.: Sleep states and behavior patterns in preterm and fullterm infants. Neuropediatrics, 11:354 (1980).

3. Curzi-Dascalova, L.: Phase relationships between thoracic and abdominal respiratory movements during sleep in 31-38 weeks CA normal infants. Comparison with fullterm (39-41 weeks CA) newborns. Neuropediatrics, 13: 15 (1982).

4. Curzi-Dascalova, L., Christova-Gueorguieva E., and Korn, G.: Les pauses respiratoires chez les enfants prématurés et les nouveau-nés à terme, normaux. Progrés en néonatalogie, $1: 19$ (1981).

5. Curzi-Dascalova, L., Gaudebout, C., and Dreyfus-Brisac, C.: Respiratory frequencies of sleeping infants during the first months of life: correlations between values in different sleep states. Early Hum. Dev., 5: 39 (1981).

6. Curzi-Dascalova, L., Monod, N., Guidasci, S., and Korn, G.: Transition veille- sommeil chez le nouveau-né et le nourrisson avant l'âge de 3 mois. Rev. EEG Neurophysiol., 11: 1 (1981).

7. Davi, M., Sankaran, K., Maccalum, M., Cates., D., and Rigatto, H.: Effect of sleep states on chest distortion and on the ventilatory response to $\mathrm{CO}_{2}$ in neonates. Pediatr. Res., 13: 982 (1979).

8. Dreyfus-Brisac, C.: Ontogenesis of sleep in human prematures after 32 weeks of conceptional age. Develop. Psychobiol., 3: 91 (1970).

9. Dreyfus-Brisac, C.: Ontogenesis of the brain bioelectrical activity and sleep organization in neonates and infants. In: Falkner F. and Tanner J. M.: Human growth, a comprehensive treatise, pp. 157-182 (Plenum Corporation, New York, 1979).

10. Dreyfus-Brisac, C. and Monod, N.: The electroencephalogram of full-term newborns and premature infants. In: Handbook of electroencephalography and clinical neurophysiology, Vol. 6, part B, pp. 6-23 (Elsevier, Amsterdam, 1975).

11. Iwase, K. and Watanabe, K.: Studies on the respiratory rate in premature babies in relation to conceptional age and sleep stage. Acta Neonatol. Japonica, 7: 56 (1971).

12. Lubchenco, L. O.: Assessment of gestational age and development at birth. Pediatr. Clin. N. Amer., 17: 125 (1970).

13. Messer, J., Erny, P., Ishe-Treussard, C., Terrade, E., Bapst-Reiter, J. and Renaud, S.: Stade de sommeil et oxygénation du nouveau-né. Arch. Fr. Pediatr., 38: 97 (1981).

14. Monod, N. et Curzi-Dascalova, L.: Les états transitionnels de sommeil chez le nouveau-né à term. Rev. EEG Neurophysiol., 3: 87 (1973).

15. Monod, N. et Pajot, N.: Le sommeil du nouveau-né et du prématuré. I. Analyse des études polygraphiques (mouvements oculaires, respiration et EEG). Biol. Neonat., 8: 281 (1965).

16. Pajot, N. Vicente, G. et Dreyfus-Brisac, C.: Technique d'enregistrement des mouvements oculaires chez les nouveau-nés. Comparison des méthodes. Journal of Electrophysiol. Technology, 2: 29 (1976).

17. Parmelee, A. H., Stern, E., and Harris, M. A.: Maturation of respiration in premature and young infants. Neuropädiatrie, 1 : 101 (1969).

18. Prechtl, H. F., Weinmann, H. and Akiama, Y.: Organization of physiological parameters in normal and neurologically abnormal infants. Neuropädiatrie, $l$ : 101 (1969).

19. Rechtschaffen, A. and Kales, A.: Manual of standardized terminology, techniques and scoring system for sleep states in human subjects. p. 204, (Government Printing Office, National Institute for Health publication, Washington D. C., United States, 1968)

20. Rigatto, H., Kalapesi, Z., Leahy, F. N., Durand, M., Maccalum, M., and Cates, D.: Chemical control of respiratory frequency and tidal volume during sleep in preterm infants. Resp. Physiol., 41: 117 (1980).

21. Saint-Anne Dargassies, S.: Le développement neurologique du nouveau-né à terme et du prématuré. p. 337 (Masson et Cie., Paris, 1974).

22. Schulte, F. J.: Apnea. Clin. Perinatol., 4: 65 (1977).

23. Siassi, B., Hodgman, J., Cabal, L. and Hon, E.: Cardiac and respiratory activity in relation to gestation and sleep states in newborn infants. Pediatr. Res., 13: 1163 (1979).

24. Request for reprints should be addressed to Dr. Lilia Curzi-Dascalova, Centres de Recherches de Biologie Foetale et néonatale, 123, bd. de Port Royal, 75014Paris, France.

25. This research was supported by CNAMTS Grant no 78-69.

26. Received for publication November $25,198 \mathrm{I}$

27. Accepted for publication June 1, 1982. 